\title{
Do processo discursivo à agenda operativa: gestão das águas e participação social no Oeste catarinense
}

From the discursive process to operational agenda: water management and social participation in the west of Santa Catarina state

\author{
Izabella Barison Matos* \\ Paulo Roberto Barbato ${ }^{* *}$ \\ Enio Mario Mendes ${ }^{* * *}$ \\ Raquel Antunes da Silva Sagaz ${ }^{* * * *}$
}

\begin{abstract}
Palavras-chave:
Água

Participação social

Meio ambiente
\end{abstract}

Keywords:

Water

Social participation

Environment
Resumo: No Brasil e no Oeste catarinense a grande disponibilidade hídrica pode gerar percepção de abundância, afetando a relação com a água. Objetivou-se apresentar reflexões sobre Seminários Regionais da Água e projeto ambiental, problematizando participação social e gestão pública. Este artigo é um relato de experiência que analisa esses dois marcos e reflexos na sociedade regional e agenda pública. Como resultados foram identificadas categorias de análise: avanços e fragilidades que denunciam pouco envolvimento da população e da gestão pública pelo tema água. A literatura apresenta tipologias de participação, sendo a mais comum o chamamento para ações das quais a sociedade não foi coautora, dificultando maior envolvimento. A experiência apontou que a gestão pública não trata a água como prioridade na agenda e que a educação ambiental pode ser um dispositivo de exercício de cidadania; reflexões corroboradas pela literatura. Conclui-se que o processo discursivo ainda é priorizado em detrimento de uma agenda operativa, tanto da sociedade quanto da gestão pública.

\begin{abstract}
In Brazil and West of Santa Catarina, the great water availability can generate perception of abundance affecting the relationship with water. The objective was to reflections on Regional Water Seminars and environmental project - problematizing social participation and public management. This article is an experience report that analyzes these two milestones and reflexes in the regional society and the public agenda. As a result, it was identified categories of analysis: advances and weaknesses that denounce little involvement of the population and public management by the water as a discussion theme. The literature presents typologies of participation, the most common being the call for actions of which the society was not co-authoring, hindering greater involvement. Public management does not treat water as a priority on the agenda. Environmental education is a device for exercising citizenship. It is concluded that the discursive process is still prioritized over the operative agenda of both society and public management.
\end{abstract}

Recebido em 29 de outubro de 2019. Aprovado em 03 de fevereiro de 2020.

\footnotetext{
* Doutora em Ciências - Saúde Pública. Docente do Programa de Pós-Graduação em Saúde Coletiva, Universidade Federal do Rio Grande do Sul, Porto Alegre (RS). Participante do Grupo da Água - Água Doce (SC), membro da Comissão Organizadora dos Seminários Regionais da Água. E-mail: <izabmatos@gmail.com>.

** Doutor em Saúde Coletiva pela Universidade Federal de Santa Catarina. Professor da Universidade Federal da Fronteira Sul (UFFS) Chapecó (SC). E-mail: <prbarbato@gmail.com>.

*** Sindicato Rural e Conselho Municipal de Desenvolvimento Rural (CMDR), Água Doce, (SC). Agrônomo da Empresa de Pesquisa Agropecuária e Extensão Rural de Santa Catarina (EPAGRI). E-mail: <eniomariomendes@gmail.com>.

**** Escola de Educação Básica Ruth Lebarbechon, Água Doce (SC). E-mail: <raquelsilvasagz@yahoo.com.br>.
} 


\section{Introdução}

O Brasil é privilegiado com relação à disponibilidade hídrica, embora a mesma não ocorra de forma homogênea, o que pode ter gerado na sociedade uma "cultura de abundância". Possivelmente se trata de um aspecto do imaginário da sociedade, que afeta ações mais conscientes com relação a tal bem natural, e que vem sendo substituído, de forma progressiva, pelo entendimento da água como um bem finito e dotado de valor econômico (BRASIL, 2019, p. 7), como um produto, ou commodity.

O dossiê Water for a sustainable world, da Organização das Nações Unidas para a Educação, a CiênciaeaCultura, informaque,em2050, semantidas as condições atuais relativas ao abastecimento e à distribuição hídrica, $70 \%$ da população mundial terão problemas de acesso à água. O alerta à América Latina e ao Caribe é que a grande prioridade seja a construção da "[...] capacidade institucional formal para gerenciar recursos hídricos e promover a integração sustentável da água" (UNESCO, 2015, p. 17, tradução nossa).

Nos últimos anos foram descritas crises hídricas que apontam má gestão das águas (FISCHER et al., 2016) ou "crise de governança" (TRINDADE; SCHEIBE; RIBEIRO, 2018, p. 39) e sinalizam a premência de a sociedade dar respostas aos problemas ambientais recorrentes. $\mathrm{O}$ debate atual sobre segurança hídrica ocorre a partir do esgotamento dos mananciais de abastecimento de água em cidades dos Estados de São Paulo, Rio de Janeiro, Bahia e Distrito Federal (BRASIL, 2019). Isso a despeito de que, desde a Constituição Federal de 1988, o País conquistou parâmetros legais que asseguram a formulação de políticas públicas protecionistas. No caso da água, em 1997, foi aprovado pelo Congresso Nacional o Plano Nacional de Recursos Hídricos (PNRH), conhecido como "Lei das Águas", Lei no 9.433 (BRASIL, 1997). O Brasil, em resposta aos anseios da comunidade internacional, tem providenciado uma lenta atualização institucional, política e tecnológica dos recursos hídricos.
O Plano preconiza a gestão compartilhada e integrada no âmbito do Sistema Nacional de Gerenciamento dos Recursos Hídricos (SNRH), cabendo à Agência Nacional de Águas (ANA) a missão de garantir segurança hídrica para o desenvolvimento sustentável brasileiro, sendo a responsável pela sua implementação. O SNRH apresenta caráter descentralizador (integrando União e estados), participativo e inovador (pela criação de comitês de bacias hidrográficas) e, na gestão, une poderes públicos nas três instâncias, usuários e sociedade civil.

Recentemente, a ANA publicou material - cujo diagnóstico remontou aos anos 1930 até a contemporaneidade e faz prospecção para 2030 oferecendo balanço hídrico (oferta e usos da água) em todos os municípios brasileiros (BRASIL, 2019). Os usos da água são divididos em categorias, a partir da importância de uso consuntivo, quer dizer, a quantidade de água que é retirada e consumida, não retornando diretamente ao curso de água original. As seis categorias são: abastecimento humano, abastecimento animal, indústria de transformação, mineração, termoeletricidade e irrigação.

Este artigo apresenta algumas análises que são fruto de reflexões decorrentes das vivências de seis Seminários Regionais da Água (SRA), realizados de 2013 a 2018, ${ }^{1}$ em Água Doce, no Meio-Oeste catarinense, e da elaboração do projeto Rio Água Doce: proteção de nascentes e ações de saneamento ambiental rural. Com base nessas experiências, parcialmente exitosas, questionase: apesar do arcabouço legal (Lei $n^{\circ}$ 9.433), de programas governamentais (Comitês de Bacias Hidrográficas) e da crise hídrica recente, o que pode explicar a baixa adesão da sociedade às ações envolvendo questões ambientais (água) e a postura apenas retórica da gestão pública, que não prioriza o tema da água na sua agenda?

Assim, o propósito deste artigo é discutir a contribuição da sociedade como força transformadora para mitigar seus próprios efeitos no meio ambiente e a atuação da gestão pública no mesmo sentido. 


\section{Métodos}

Foram tomados como unidade de análise empírica a experiência dos seis Seminários Regionais da Água (SRA), realizados de 2013 a 2018, e o projeto ambiental Rio Água Doce: proteção de nascentes e ações de saneamento ambiental rural, todos em Água Doce, município localizado no Meio-Oeste de Santa Catarina. Foram aprimorados processos participativos em iniciativas ambientais, ao mesmo tempo que se reavivou o debate sobre a água, analisando o pensar e o agir como indicadores do grau de comprometimento dos gestores $\mathrm{e}$ políticos municipais, envolvendo o Comitê da Bacia do Rio do Peixe na direção de uma agenda mais operativa e menos retórica.

Aproximações entre grupos representativos da população da educação básica e superior, os setores produtivos rural e urbano, os poderes executivo e legislativo municipais, entre outros, além da contribuição da academia, ofereceram as bases para possibilidades de formulação de políticas públicas a partir de diferentes ações de educação ambiental. A exemplo do que relatam Minayo e Miranda (2002) em situação semelhante, no caso em pauta foram identificadas possibilidades de ampliação da capacidade de discussão sobre a temática ambiental - água - e estabelecidas parcerias e alguns compromissos com diferentes instituições e representações da sociedade, ao longo desses sete anos.

O método participativo, que permeou todo o processo de realização dos SRA e do projeto ambiental, valeu-se do conceito de aprendizagem social, que consiste em "aprender no e a partir do ambiente, mediante reflexão crítica dos problemas e desafios comuns a todos e dos conhecimentos de que dispomos para resolvê-los [...] a fim de negociar interesses para seu uso democrático e sustentável" (SANTOS; JACOBI, 2017, p. 524). Além de se envolverem as diferentes representações sociais e institucionais citadas, foram mobilizadas parcerias regionais (Comitê da Bacia do Rio do Peixe) e estaduais (Secretaria de Estado de Desenvolvimento Econômico Sustentável (SDS) e Instituto do Meio Ambiente (IMA) de Santa Catarina).
Além de quatro ações ambientais, que serão descritas, o grupo interinstitucional GT da Água, que conduziu o processo, exerceu o papel de provocador do debate e de canalizador de reivindicações ambientais. Interessante observar que, considerando-se que a democracia participativa não tem conseguido dar conta das demandas da sociedade, a participação direta de alguns atores sociais, ao exercerem a cidadania, parece ter sido um acontecimento (TENÓRIO, 2012) - no caso em pauta, a atuação do grupo (GT da Água).

Foram realizadas análises críticas destes dois marcos: Seminários Regionais da Água e projeto ambiental, considerados mais significativos, que provocaram reflexos na agenda pública e na sociedade, revelando duas categorias empíricas: avanços e fragilidades no processo. Dentre as fragilidades destacam-se: pouco interesse $\mathrm{da}$ sociedade pelo tema; envolvimento apenas protocolar do poder público municipal; entraves na representação do legislativo municipal; interesse reduzido por parte da representação da empresa responsável pela gestão municipal da água; desconhecimento da legislação pelos envolvidos; e dificuldades administrativas e legais. Os avanços identificados foram: formação de Grupo de Trabalho (GT da Água) interinstitucional e multiprofissional; ampliação de parcerias que formaram rede de apoio na região e no Estado; elaboração de projeto ambiental para obtenção de financiamento compensação de multas ambientais/Polícia Militar; projeção do município de Água Doce no cenário estadual (Secretaria de Estado de Desenvolvimento Econômico Sustentável (SDS) e Agência Nacional de Águas (ANA); e instrumentalização técnicocientífica e legal do GT da Água.

Ao se cotejarem os dados empíricos e a literatura, avança-se no entendimento de que iniciativas que proporcionem maior envolvimento da sociedade - desde a elaboração de projetos/ações ambientais e não somente na execução de ações prontas ou referendá-las - podem ser estratégia mais exitosas. Por outro lado, a gestão pública parece se interessar pelo tema quando vislumbra fontes de financiamento, mas sua postura retórica se revela no trato protocolar sobre o tema, quando 
provocada a se posicionar publicamente. Conceitos de participação social, políticas públicas e educação ambiental foram utilizados, oportunizando maior conhecimento acerca das análises das experiências.

\section{Contextualizando: o Município de Água Doce e sua “abundância” de recursos hídricos}

Água Doce, localizado no Meio-Oeste catarinense, é um dos maiores municípios de Santa Catarina em extensão territorial e, em 2017, segundo dados do IBGE, contava com 7.154 habitantes, sendo $49 \%$ no espaço urbano e 51\%, no rural. A economia, com base na agricultura e na pecuária, atinge, aproximadamente, $83 \%$ da arrecadação municipal, segundo avaliação da Federação Catarinense de Municípios (FECAM) (2018), com desempenho econômico médio - 0,587 . $^{2}$

$\mathrm{O}$ Índice de Desenvolvimento Municipal Sustentável (IDMS), ferramenta que apresenta indicadores (sociais, econômicos, culturais) que oferecem diagnóstico do grau de desenvolvimento de um território, apontou, também, em 2018, uma posição de desempenho médio: 0,657 (FEDERAÇÃO CATARINENSE DE MUNICÍPIOS, 2018). No entanto, o Índice GINI - um instrumento para medir o grau de concentração de renda entre os mais pobres e os mais ricos, no qual o valor zero representa menor grau de igualdade (INSTITUTO DE PESQUISA ECONÔMICA APLICADA, 2004) -, mostrouse baixo: 0,460 (FEDERAÇÃO CATARINENSE DE MUNICÍPIOS, 2018). A estrutura fundiária é caracterizada por grandes (10\%), médias (13\%) e pequenas $(77 \%)$ propriedades (CONSELHO MUNICIPAL DE DESENVOLVIMENTO RURAL, 2012), contemplando agricultura familiar, e cinco assentamentos da reforma agrária.

Com milhares de fontes e nascentes, o município é fornecedor de água para consumo humano/animal e geração de energia elétrica para as regiões Oeste e Meio-Oeste catarinenses (ZAGO; PAIVA, 2008), além de integrar quatro das 23 bacias hidrográficas do Estado. São elas: Bacia hidrográfica do Rio do Peixe, Bacia hidrográfica do Rio Jacutinga, Bacia hidrográfica do Rio Chapecó e Bacia hidrográfica do Rio Irani. Os principais rios que percorrem o município são: Chapecó, Chapecozinho, Roseira, do Mato, Jacutinga, Estreito e Bom Retiro; possui, ainda, as nascentes dos rios Salto Veloso, Irani e Jacutinga, Água Doce, Cambuim, Ribeirão Trancado, Prato Raso, Lajeado Bonito e Passo da Encerra, além de outros de menor volume de água. 


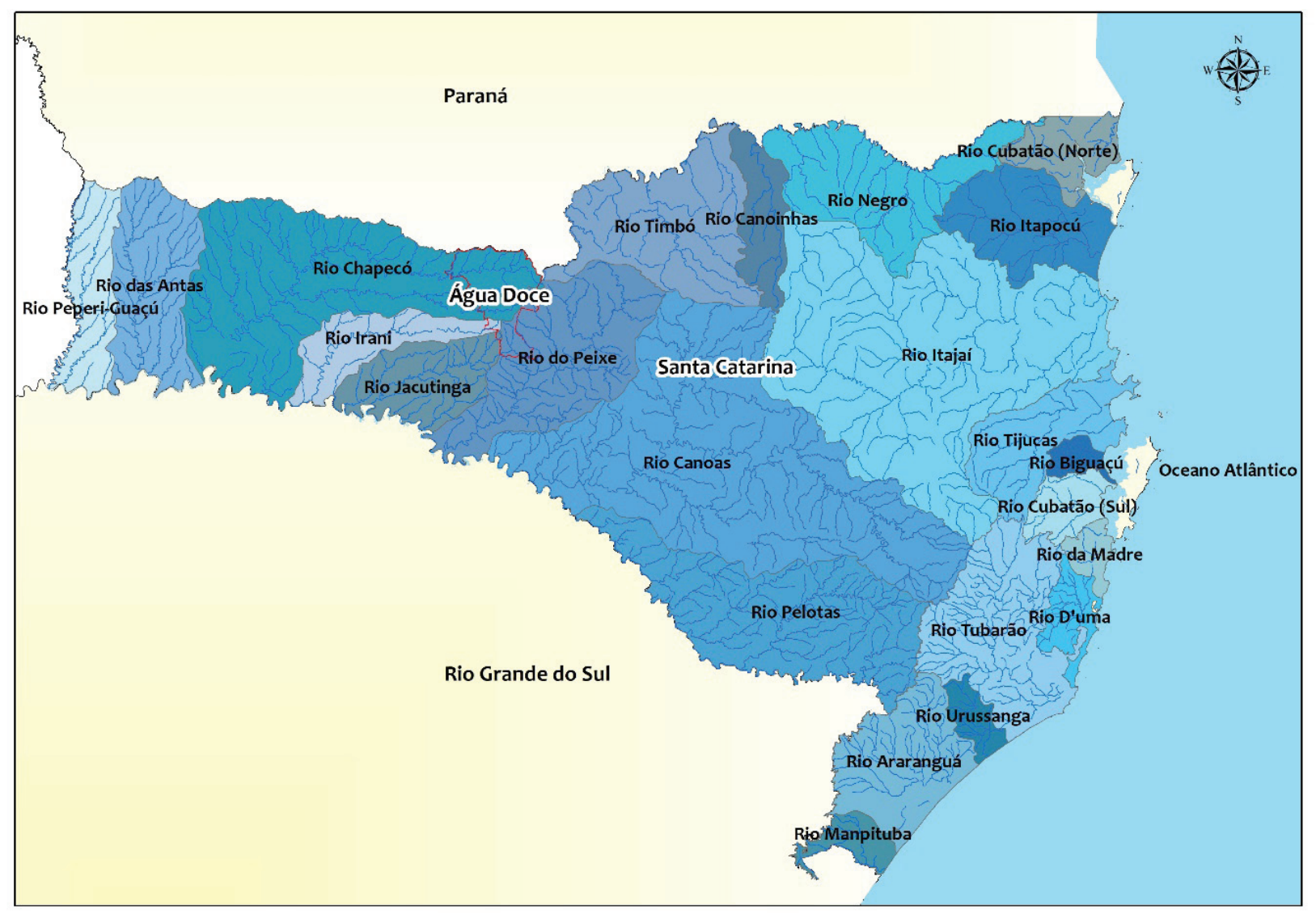

Figura 1: Mapa das bacias hidrográficas do Estado de Santa Catarina Fonte: Elaborado a partir das bases cartográficas da SDS, em 2019.

Com relação a rios e nascentes, o município pertence à Bacia Hidrográfica do Rio do Peixe, um dos grandes afluentes do Rio Uruguai, o qual faz parte do Aquífero Guarani, a mais importante reserva de água doce subterrânea localizada na América do Sul. No Brasil, o Aquífero Guarani encontra-se no subsolo dos Estados de São Paulo, Goiás, Mato Grosso, Mato Grosso do Sul, Paraná, Rio Grande do Sul e Santa Catarina e essa "reserva de água está protegida de contaminações e infiltrações por uma camada de rocha basáltica" (LIMA; MAFRA; RECH, 2016, p. 8).

\section{Resultados: do processo discursivo à agenda operativa}

A partir da configuração hidrográfica anteriormente apresentada, foi criado, por iniciativa de um agrônomo da Empresa de Pesquisa Agropecuária e Extensão Rural de Santa Catarina
(EPAGRI) e Secretário da Agricultura do Município, o $1^{\circ}$ Seminário Regional da Água, em 2013. Com diversos formatos, embora sempre focados em discussões sobre a sustentabilidade e o uso responsável da água, aconteceram edições anuais até 2018, contando com diferentes representações: gestão pública, poder legislativo municipal, setor educacional, setor produtivo-rural e urbano, bem como gestores de águas do Município e região, envolvendo, nesses sete anos, cerca de 1.100 pessoas.

Os Seminários Regionais da Água (SRA) foram eventos que utilizaram estratégias participativas envolvendo educação básica e superior, sindicatos rurais, grupos populacionais, conselhos de desenvolvimento rural, setor produtivo rural e urbano, poderes legislativo e executivo, o Comitê da Bacia Hidrográfica do Rio do Peixe, o Comitê da Bacia hidrográfica do Rio Chapecó, a Secretaria de Estado de Desenvolvimento Social Sustentável (IDS) e o Instituto do Meio Ambiente 
(IMA), que apresentaram postura de cooperação no processo. A descrição, no Quadro 1, com histórico trazendo os temas, metodologias utilizadas, público participante e encaminhamentos realizados, demonstra a sua relevância.

Quadro 1: Seminários Regionais da Água: histórico

\begin{tabular}{|c|c|c|c|c|c|}
\hline Evento & Ano & Tema principal & Metodologia & Público & Encaminhamentos e ações \\
\hline $1^{\circ}$ & 2013 & $\begin{array}{l}\text { Água: desafios para a } \\
\text { preservação. }\end{array}$ & $\begin{array}{l}\text { Palestras. } \\
1 \text { etapa. }\end{array}$ & 190 & $\begin{array}{l}\text { Levantamento sobre água para } \\
\text { consumo - em assentamento rural. }\end{array}$ \\
\hline $2^{\circ}$ & 2014 & $\begin{array}{l}\text { Melhoria da qualidade da } \\
\text { água. }\end{array}$ & $\begin{array}{l}\text { Palestras. } \\
1 \text { etapa. }\end{array}$ & 50 & $\begin{array}{l}\text { Relatório - situação dos poços } \\
\text { artesianos - Bacia do Rio Jacutinga. }\end{array}$ \\
\hline $3^{\circ}$ & 2015 & $\begin{array}{l}\text { Inovação para a } \\
\text { Sustentabilidade. }\end{array}$ & $\begin{array}{l}\text { Palestras. } \\
1 \text { etapa. }\end{array}$ & 200 & $\begin{array}{l}\text { Financiamento do SRA, } \\
\text { visita técnica à Itaipu: "Água Boa”. }\end{array}$ \\
\hline $4^{\circ}$ & 2016 & $\begin{array}{l}\text { Proteção de nascentes: } \\
\text { tecnologia e inovação para } \\
\text { a preservação. }\end{array}$ & $\begin{array}{l}\text { Processos mais } \\
\text { participativos. } \\
2 \text { etapas. }\end{array}$ & 232 & $\begin{array}{l}\text { Aproximação: Universidade e } \\
\text { Educação Básica - Exposição de } \\
\text { maquetes e pôsteres. } \\
\text { Ações EA: } \\
\text { 1. Limpeza do Rio ( } 2 \text { edições); } \\
\text { 2. Água boa para beber - } \\
\text { assentamento; } \\
\text { 3. Revitalização do Rio Trancado } \\
\text { (2 edição), } \\
\text { financiamento do SRA, } \\
\text { e-book sobre as experiências do } 4^{\circ} \\
\text { SRA. }\end{array}$ \\
\hline $5^{\circ}$ & 2017 & $\begin{array}{l}\text { Água: proteção de } \\
\text { nascentes em Água Doce } \\
\text { (SC) - promovendo } \\
\text { cultura ambiental, criando } \\
\text { políticas públicas. } \\
\text { Relatos: Projeto } \\
\text { Camboriú e PSA- } \\
\text { Secretaria de Estado } \\
\text { do Desenvolvimento. } \\
\text { Econômico Sustentável } \\
\text { (SDS). }\end{array}$ & $\begin{array}{l}\text { Processos mais } \\
\text { participativos. } \\
2 \text { etapas. } \\
\text { Relatos de } \\
\text { experiência. }\end{array}$ & 191 & $\begin{array}{l}\text { 1. Exposição de maquetes e pôsteres; } \\
\text { 2. Criaça de Grupo de Trabalho - } \\
\text { Projeto Água - financiamento - Polícia } \\
\text { Ambiental; } \\
\text { 3. Revitalização Rio Trancado ( } 1 \text { edição); } \\
\text { 4. Projeto Ambiental Água Doce, visita } \\
\text { técnica - São Bento do Sul - PSA. }\end{array}$ \\
\hline $6^{\circ}$ & 2018 & $\begin{array}{l}\text { Cuidando da água e } \\
\text { retribuindo quem protege. } \\
\text { Projeto Rio Vermelho - } \\
\text { São Bento do Sul e PSA/ } \\
\text { SDS. }\end{array}$ & $\begin{array}{l}\text { Processos } \\
\text { Participativos. } \\
2 \text { etapas. } \\
\text { Relatos de } \\
\text { experiência. }\end{array}$ & $\begin{array}{l}\text { 1a Etapa: } \\
91 . \\
2^{\text {a Etapa }} \\
\text { setembro } \\
\text { de } 2018: \\
120 .\end{array}$ & $\begin{array}{l}\text { 1. Elaboração de Projeto - Produtor } \\
\text { de Água Rio Água Doce; } \\
\text { 2. Exposição de maquetes e pôsteres. }\end{array}$ \\
\hline
\end{tabular}

Fonte: Elaborado pelos autores a partir dos Relatórios Anuais dos Seminários Regionais da Água de 2013 a 2018.

De 2013 a 2015 os seminários tiveram formato tradicional, com palestras seguidas de discussão. Ao se avaliar o impacto no cotidiano do município, chegou-se à conclusão de que o aporte não estava sendo tão significativo, pois as discussões se encerravam com os Seminários. Considerandose que o tema da água extrapola as fronteiras de um único município e precisa ser tratado de maneira integrada, e também a necessidade de ampliar iniciativas de educação ambiental (EA), a partir da $4^{\mathrm{a}}$ edição (2016) oportunizou-se aos habitantes locais não somente elencar e priorizar demandas, mas também realizar ações focadas no enfrentamento da problemática ambiental voltada à água. Adotou-se um formato mais propositivo e incentivador de ações protagonistas dos diferentes segmentos sociais envolvidos, com socialização das intervenções realizadas.

Esse novo formato, além de sinalizar o envolvimento e a aproximação entre educação básica 
(escolas municipais e estaduais), educação superior (universidade federal), segmentos da população, agentes políticos, instituições governamentais e setor produtivo-econômico, tanto urbano quanto rural, visou ao estímulo à autonomia, ao diálogo e a certa reinvenção do cotidiano relativo ao ambiente, cujo foco é a água.

Neste trabalho serão apresentadas quatro ações de educação ambiental originárias dos SRA: 1. Limpeza do Rio Água Doce, no perímetro urbano - duas edições; 2. Água Boa de Beber - proteção de nascente em assentamento; 3. Revitalização do Ribeirão Trancado - na zona rural; e 4. Projeto ambiental - Rio Água Doce: proteção de nascentes e ações de saneamento ambiental rural. As três primeiras ações citadas, e relatos dos SRA de 2013 a 2016, foram descritos em e-book (MATOS et al, 2017), cujo objetivo foi socializar as vivências, proporcionando acesso da produção aos participantes dos referidos Seminários, sendo patrocinado pela FAPESC, por meio do Edital Pró-Eventos. Também algumas análises foram apresentadas em eventos nacionais e internacionais.

\section{Ação 1. Mobilização para limpeza do leito e proteção das margens do Rio Água Doce}

A partir da constatação que a quantidade de resíduos, dos mais diversos tipos e das mais variadas origens, depositados às margens e no leito do Rio Água Doce, no perímetro urbano, estavam poluindo as águas e obstruindo o fluxo normal, foram realizadas duas edições de mobilização, impulsionadas pelos SRA. O objetivo foi dar visibilidade ao problema, envolvendo diferentes segmentos da comunidade e sensibilizando sobre a necessidade de limpeza do rio e a correta destinação dos resíduos.

Nos meses de setembro e outubro de 2016 ocorreu o processo de mobilização. Foram adotadas como estratégias nesse processo:1. Reunião de apresentação da proposta e solicitação de apoio das entidades participantes; 2. Ampla divulgação das ações convidando a população e informando, com panfletos, moradores das margens do Rio Água Doce; 3. Divisão dos grupos e designação dos coordenadores responsáveis pelo chamamento e organização dos participantes nos respectivos trechos de extensão da limpeza; 4. Organização da infraestrutura (caminhões para coleta e acompanhamento do Corpo de Bombeiros) e materiais necessários (sacos, luvas e coletores); 5. Realização das ações de limpeza do leito e das margens; 6. Avaliação das ações.

Resultaram das duas mobilizações: participação de 95 pessoas de diferentes segmentos da comunidade; limpeza de sete quilômetros das margens e leito do Rio; recolhimento de três cargas de caçamba com resíduos. Essas iniciativas oportunizaram vivência de educação ambiental (EA) com o Corpo de Bombeiros, escolares, professores da Educação Básica e Superior, o Grupo da terceira Idade, operadores de políticas públicas, industriários, lojistas, sindicalizados, conselheiros, entre outros.

A avaliação apresentou dados positivos, entre eles: sensibilização quanto à limpeza do rio e à correta destinação dos resíduos; mobilização de um número relevante de pessoas de diferentes segmentos da sociedade; e envolvimento interinstitucional, do setor produtivo, dos poderes executivo e legislativo municipais, bem como da educação básica e universitária. No entanto, foram duas edições pontuais, que não tiveram continuidade e não contou com envolvimento de famílias ribeirinhas.

\section{Ação 2. “Água boa para beber”: Escola Municipal Assentamento - $1^{\circ}$ de agosto}

As vivências em educação ambiental de proteção de nascente aconteceram em 2016, em um assentamento do INCRA implantado no ano 2000, com 52 famílias de agricultores em atividades agropecuárias, sendo que algumas propriedades apresentavam falta de água em certos períodos do ano. Metodologicamente o processo ocorreu pela iniciativa de uma professora, que mobilizou estudantes, pais e agrônomos. Foram realizadas as seguintes atividades: 1. Estudo do tema água e a proteção de nascentes - com mapa mundi e 
estratégias participativas; 2. Expedição in loco; 3. Consulta à totalidade das famílias residentes (13) para identificar: a) quais usavam água de fonte ou de poço; b) de que forma a água chegava até as casas; e c) se a água era suficiente para o consumo da família e dos animais; 4 . Construção de proteção para a nascente que abastece a escola e o centro comunitário; 5 . Coleta de amostra para análise das condições de potabilidade da água dessa nascente; e 6. Registro da experiência para socializar o aprendizado. $\mathrm{O}$ trabalho de proteção da nascente aconteceu com o envolvimento da comunidade escolar, Secretaria da Agricultura, Secretaria de Obras, Sindicato dos Trabalhadores Rurais de Água Doce e orientação técnica da EPAGRI.

Como resultados alcançados, foi realizada a proteção da nascente no Modelo Caxambú, tecnologia desenvolvida por técnicos da EPAGRI, com grande vantagem ambiental, pois há garantia de que a nascente não seja contaminada por agentes externos, uma vez que filtra e canaliza a água para residências, escolas e outros. Outra vantagem, além de ser muito simples a sua instalação, é o seu baixo custo (SANTA CATARINA, 2012). Da consulta às 13 famílias obteve-se as seguintes informações: 11 tinham água de poço, e duas, água de fonte; para 11 famílias o acesso à água ocorria por bomba, e nas outras duas a água chegava por gravidade até a casa. Para apenas seis famílias havia água suficiente. Três meses após, a análise da amostra de água da nascente protegida apresentou que o padrão para consumo humano ainda estava insatisfatório, pelo fato de ser constatada dosagem de fluoreto abaixo de $0,7 \mathrm{mg} / \mathrm{l}$, sendo necessária a instalação de um equipamento dosador, que foi providenciado.

\section{Ação 3. Revitalização do Ribeirão Trancado - Escola de Educação Básica Ruth Lebarbechon}

A Escola de Educação Básica Ruth Lebarbechon tem alunos oriundos das comunidades do interior do Município, por onde o Ribeirão Trancado passa. Sensível à necessidade de promover conhecimento e ações de educação ambiental específicas, direcionadas à proteção de nascentes - como parte do aprendizado escolar -, uma professora propôs um projeto com a intenção de aplicar os conceitos científicos básicos sobre a importância da mata ciliar para a manutenção da vida e a proteção de nascentes, rios e demais cursos d'água.

O projeto foi elaborado e iniciado em 2016, constando a detecção do problema in loco, com a realização de pesquisas no cotidiano escolar no componente curricular de Biologia, com aporte de outras áreas do conhecimento - sobre a importância da proteção das nascentes -, embasando a decisão da recuperação da nascente. Entre julho e setembro de 2017 houve expedições dos estudantes, docentes e direção da Escola para as quais foram contactados proprietários de terras em áreas do percurso do Ribeirão. Estes foram sensibilizados e acolheram o Projeto, colaborando com a iniciativa, que realizou o plantio de mudas de pitanga, guajuvira, cedro, cereja, goiaba, guabiju, entre outras, nas suas margens.

O processo foi documentado por meio de relatórios e imagens e apresentado em eventos científicos nacionais e internacionais. Destaca-se o empenho da comunidade escolar em planejar formas de garantir a realização das ações de educação ambiental, uma vez que parte delas ocorreu fora do ambiente escolar, envolvendo apoio logístico para deslocamentos, doações de mudas, obtenção de materiais e habilidade para obter apoios interinstitucionais.

\section{Ação 4. Projeto Rio Água Doce: proteção de nascentes e ações de saneamento ambiental rural}

Em 2017, como parte da programação do $5^{\circ}$ SRA, foi criado o Grupo de Trabalho (GT) da Água, formado por participantes que se candidataram espontaneamente a integrá-lo, o qual se responsabilizou pela elaboração de proposta de política pública ambiental. Isso ocorreu a partir das discussões sobre política nacional de Pagamento de Serviços Ambientais (PSA) da Agência Nacional de Águas (ANA). Assim, incentivado pela parceria com a Secretaria de Estado do Desenvolvimento 
Econômico e Sustentável (SDS) e em visita técnica ao Projeto Rio Vermelho, em São Bento do Sul, SC, primeiro município catarinense a implantar proposta que é referência nacional, o GT da Água deu início à elaboração do projeto.

A intenção inicial era a definição de uma política pública de PSA, passível de obtenção de recursos federais, com diversas experiências em municípios brasileiros. No entanto, a procuradoria do Município de Água Doce, presente no evento, informou que se tratava de um projeto que caberia ao executivo municipal submeter à apreciação do legislativo, caracterizando-se em iniciativa que envolvia recursos financeiros não previstos no orçamento.

Diante disso, o GT se mobilizou em outra direção, com a parceria da Secretaria de Estado de Desenvolvimento Sustentável e, posteriormente, do Comitê da Bacia Hidrográfica do Rio do Peixe, encontrando alternativa de fomento na legislação estadual, junto à Polícia Ambiental - Portaria ${ }^{\circ}$ 002/CPMA/PMSC/2016 ${ }^{3}$ (SANTA CATARINA, 2016). Esta previa a compensação de multas ambientais, estabelecendo referências para a orientação e aprovação de projetos de conversão de multa simples em serviços de preservação, melhoria e recuperação da qualidade do meio ambiente.

Assim, com apoio técnico da Diretoria de Mudanças Climáticas, que elaborou mapas de áreas prioritárias para conservação e restauração do solo e análise ambiental do Município, por meio de Sistema de Informações Geográficas (SIG) - no caso do software ARCGIS 9.0 -, foi iniciada a elaboração do projeto. Com reuniões sistemáticas do GT da Água, decidiu-se pela atuação em propriedades rurais localizadas na Microbacia do Rio Água Doce, contemplando 10 ações de proteção de nascentes e cinco de saneamento ambiental rural em áreas de alta prioridade para conservação ambiental, equivalentes a 24 hectares.

Em 22 de março de 2019, Dia Mundial da Água, o referido projeto foi oficialmente apresentado por integrantes do GT da Água, ao poder executivo municipal e demais convidados regionais e locais. Na sequência, a Prefeitura Municipal o submeteu à Polícia Militar Ambiental para ser analisado e serem obtidos recursos provenientes das multas. No Dia Municipal da Água, 8 de julho, o projeto foi apresentado ao poder legislativo municipal em sessão privilegiando o tema e que contou com a presença de um representante do Comitê da Bacia do Rio do Peixe, o qual abordou o tema da gestão das águas na região Meio-Oeste catarinense.

Avançar a etapa de discussões, passar pela fase do chamamento de "trabalho braçal" da sociedade e chegar a um envolvimento mais direto nas decisões é um registro importante desse processo. Isso porque o Município de Água Doce não contava com nenhum projeto ambiental passível de ser submetido a fontes de fomento; assim, foi pensada uma alternativa que obtivesse recursos financeiros externos para financiamento de projetos e ações.

O que se quer é continuar refletindo sobre a água, a fim de obter certo consenso da gestão municipal e maior sensibilização da sociedade aguadocense acerca do tema ambiental. Nessa direção, o GT representa certo ineditismo no cenário político e na sociedade local e regional ao propor tal projeto ambiental, fruto do empenho de agrônomos, professoras da educação básica e universitária e gestores públicos, e que avançou, um pouco mais, no sentido de conseguir produzir uma agenda operativa.

Assim, foram identificados avanços e fragilidades nesse processo. Como avanços citam-se: formação de GT interinstitucional e interdisciplinar; ampliação de parcerias; elaboração de projeto ambiental para obtenção de financiamento compensação de multas ambientais/Polícia Militar; e projeção estadual do Município de Água Doce. Com relação às fragilidades elencam-se: a lenta mobilização de outros segmentos da sociedade, para além do educacional; o envolvimento protocolar do poder público municipal; a descontinuidade na representação do poder legislativo municipal; o pouco interesse da empresa responsável pela gestão municipal da água; o desinteresse progressivo da sociedade pelo tema água; o desconhecimento da legislação e das possibilidades de financiamento; os entraves administrativos legais na condução dos encaminhamentos, entre outros. 


\section{Discussão: entre a retórica e o cotidiano: o que diz a literatura?}

O Relatório da Unesco de 2015 recomenda que para preservar a água como bem natural, devem-se priorizar a educação ambiental, as práticas preservacionistas de proteção das nascentes, a criação de políticas públicas, bem como iniciativas concomitantes para assegurar água de boa qualidade e em quantidade suficiente para as atuais e futuras gerações.

Partindo das categorias empíricas - avanços e fragilidades -, elegeram-se conceitos teóricos sobre participação social, políticas públicas e educação ambiental para maior entendimento do questionamento levantado incialmente: apesar do arcabouço legal de programas governamentais e da crise hídrica recente, o que pode explicar a baixa adesão da sociedade às ações envolvendo questões ambientais (água) e a postura retórica da gestão pública, que não prioriza o tema da água na sua agenda?

A esse respeito, estudo sobre a governança da água junto a comitês de duas bacias hidrográficas no Meio-Oeste catarinense informa que, em termos de legislação, o Brasil apresenta "vício" em razão do excesso de normatizações que não se traduzem na prática. Os autores salientam que "a participação do poder público, especialmente o municipal, tem sido um grande desafio [...] além da necessidade de criar estímulos que proporcionem maior participação da sociedade" (TRINDADE; SCHEIBE; RIBEIRO, 2018, p. 48).

Nessa direção, pode-se dizer que, embora os gestores tenham "competências regulatórias, tributárias e de fiscalização na gestão ambiental local, podendo licenciar ou inibir determinados usos segundo seus interesses" (TRINDADE; SCHEIBE, 2019, p. 14), as experiências e a literatura têm apontado que a atuação ainda é incipiente e retórica, tratando-se de um desafio a ser superado.

Apesar de as avaliações dos SRA terem sido positivas - e demonstrarem estratégias cada vez mais participativas -, percebeu-se que, quanto maior era a adesão da comunidade escolar, menor era a participação das outras representações. Também, ao dimensionar os reflexos no cotidiano ambiental do município, verificou-se que as discussões se encerravam nos Seminários. As questões ambientais parecem não fazer parte da agenda nem individual nem coletiva; talvez a baixa percepção do risco ambiental (FONSECA et al., 2007), aliada a barreiras na comunicação (TRINDADE; SCHEIBE; RIBEIRO, 2018), sejam justificativas para entender o que se passa.

Os três últimos SRA com apresentações de trabalhos multidisciplinares dos escolares da educação básica pública, remetendo um pouco ao formato de "feira de ciências", podem ter sido vistos como "coisa de aluno", "trabalho de escola" e, como tal, sem grande apelo a outros públicos. Mas, também, podem ser reveladores de fragilidades na participação social, uma vez que já estava pronta a elaboração da proposta dos SRA.

Gohn (2011), ao se referir às experiências para além do espaço formal da escola, sugere que os projetos pedagógicos devam ter eixos identitários singulares, respeitando a cultura sociopolítica local, revendo o conceito de participação e a relação entre escola e comunidade. Para a autora, movimentos similares aos descritos anteriormente podem revelar diferentes aprendizagens. São elas: prática, teórica, técnica-conceitual e política. Assim, a aprendizagem prática ocorre no sentido da organização e de como participar; a teórica se realiza ao serem abordados conceitos-chave que podem empoderar os envolvidos e dar condições para sua realização prática; a técnica-conceitual se efetiva quando oferece condições para apropriação de explicações do funcionamento da burocracia pública e das leis que regulamentam as questões em pauta; por fim, a aprendizagem política adensa a compreensão do ciclo das políticas e seu acompanhamento (GOHN, 2011).

A respeito das políticas públicas, pode-se dizer que são uma ação intencional que consiste em diferentes estágios: definição de agenda; identificação, avaliação e seleção de alternativas possíveis; formulação; execução, implementação 
e avaliação (SOUZA, 2007). Nesse momento, Água Doce está no estágio de sensibilização para a inserção na agenda pública da formulação de política pública municipal, a fim de propor enfrentamento aos problemas relativos à água. A dimensão política configurou-se na articulação e no exercício da cidadania, proporcionados pela criação de diversos cenários estimuladores, com exercício tanto individual quanto coletivo, interinstitucional e multiprofissional, recomendados por Santos e Jacobi (2017).

Retomando o questionamento acerca do pouco envolvimento da sociedade e dos gestores públicos nas temáticas envolvendo o meio ambiente, uma das explicações para tais posturas pode ser o fato de que o discurso ambientalista, no Brasil, é muito recente. Embora tenha havido avanços no sentido da aquisição de maior consciência ambiental, uma vez que temas ambientais passaram a ser priorizados "tanto para agências de fomento públicas quanto para empresas e ONGs", conforme demonstrou a pesquisa de De Marco e Trevisol (2007, p. 98), a sociedade e seus representantes, no executivo e legislativo municipais - no caso em pauta - estão muito distantes de um envolvimento esperado.

Ainda falta alcançar uma "racionalidade ambiental" (GOERGEN, 2010, p. 20) que possa integrar, conforme preconiza Leff (2003, p. 25), "[...] os potenciais da natureza, os valores humanos e as identidades culturais em práticas produtivas sustentáveis" Para compreender melhor o que se passa, o autor afirma que se trata de uma crise de conhecimento (LEFF, 2003); mais precisamente, diga-se, da falta dele.
$\mathrm{Na}$ contemporaneidade existe uma crise hídrica que denuncia a má gestão pública e revela o peso do modelo econômico e o impacto de aspectos sociais e hábitos culturais (FISCHER et al., 2016) que o ser humano insiste em manter. Historicamente, a água passou a ser vista como recurso hídrico e não mais como um bem natural insubstituível (BORGES; SANTOS, 2012), tornando-se importante a problematização dessa perspectiva equivocada, em diferentes fóruns e gerações.

Os Seminários Regionais da Água criaram uma rede social, com conexão e vínculos, estabelecendo alianças ao ampliarem parcerias. $\mathrm{Na}$ concepção de Trindade, Scheibe e Ribeiro (2018, p. 55), trata-se de uma cooperação em rede cujo intento foi o convencimento do governo municipal sobre a pertinência do tema. Assim, as ações aqui descritas e brevemente analisadas apresentaram certo protagonismo social na realização de ações de educação ambiental e proposição de criação de dispositivos legais ao executivo municipal na busca de soluções, utilizando metodologias participativas mais envolventes.

A participação social tem sido objeto de análises de diferentes autores, em diversas realidades. Rozemberg (2002) elenca cinco níveis se reportando a diferentes estudos acerca de ações de saúde coletiva, considerando-se qual ambiente está aí contemplado. Já Pretty (1995) descreve sete níveis referindo-se a ações no espaço rural como referência. Entendendo que as duas abordagens podem ser complementares, foi organizado o Quadro 2, adaptado ao interesse dos autores deste artigo na análise aqui proposta. 
Quadro 2: Níveis e tipologias de participação social, com características e identificação das ações/projetos vivenciados

\begin{tabular}{|c|c|c|c|c|}
\hline Níveis & $\begin{array}{l}\text { Tipologia de } \\
\text { participação }\end{array}$ & Características & Exemplos & $\begin{array}{l}\text { Vivências, Seminários } \\
\text { e Projeto ambiental }\end{array}$ \\
\hline $1^{\circ}$ & Passiva. & $\begin{array}{l}\text { Mera exposição das ações a } \\
\text { serem realizadas aos usuá- } \\
\text { rios. }\end{array}$ & $\begin{array}{l}\text { Frequência a eventos, assina- } \\
\text { tura de presença dos partici- } \\
\text { pantes. }\end{array}$ & $\begin{array}{l}1^{\circ}, 2^{\circ} \text { e } 3^{\circ} \text { Seminários } \\
\text { Regionais da Água. }\end{array}$ \\
\hline $2^{\circ}$ & $\begin{array}{l}\text { Envolvimento } \\
\text { indireto. }\end{array}$ & $\begin{array}{l}\text { Não há influência na defi- } \\
\text { nição dos problemas e dos } \\
\text { procedimentos. } \\
\text { A população dá respostas } \\
\text { aos desafios propostos pelos } \\
\text { profissionais externos. }\end{array}$ & $\begin{array}{l}\text { Atuação direcionada aos temas } \\
\text { de interesses previstos pela co- } \\
\text { ordenação das ações/eventos. }\end{array}$ & $\begin{array}{l}4^{\circ}, 5^{\circ} \text { e } 6^{\circ} \text { Seminários } \\
\text { Regionais da Água. }\end{array}$ \\
\hline $3^{\circ}$ & $\begin{array}{l}\text { Envolvimento } \\
\text { funcional. }\end{array}$ & $\begin{array}{l}\text { Atuação pelo trabalho "bra- } \\
\text { çal”, população é executora } \\
\text { física nas atividades pré- } \\
\text {-estabelecidas. } \\
\text { É comum a não disposição } \\
\text { para continuidade após o } \\
\text { término do recurso. } \\
\text { Promove a autodependência. }\end{array}$ & $\begin{array}{l}\text { Iniciativas externas na defini- } \\
\text { ção das ações. } \\
\text { Recebimento de recursos fi- } \\
\text { nanceiros/materiais. }\end{array}$ & $\begin{array}{l}\text { Ações de limpeza do } \\
\text { Rio Água Doce (2016). } \\
\text { Projeto ambiental pro- } \\
\text { posto. }\end{array}$ \\
\hline $4^{\circ}$ & Interatividade. & $\begin{array}{l}\text { Envolvimento ativo nas de- } \\
\text { cisões, nas análises e na con- } \\
\text { dução do processo. }\end{array}$ & $\begin{array}{l}\text { Envolvimento nas decisões } \\
\text { e na realização das ações em } \\
\text { conjunto. } \\
\text { Aprendizagem conjunta. }\end{array}$ & \\
\hline $5^{\circ}$ & $\begin{array}{l}\text { Mobilização } \\
\text { autônoma. }\end{array}$ & $\begin{array}{l}\text { População toma iniciativa, } \\
\text { independentemente das ins- } \\
\text { tituições. } \\
\text { Estabelecimento de redes } \\
\text { externas para obtenção de } \\
\text { recursos e apoio técnico. }\end{array}$ & $\begin{array}{l}\text { Sociedade delibera sobre prio- } \\
\text { ridades/recursos/investimen- } \\
\text { tos do projeto ou ações; bem } \\
\text { como dos recursos e das áreas } \\
\text { prioritárias. }\end{array}$ & \\
\hline
\end{tabular}

Fonte: Adaptado de Pretty (1995) e Rozemberg (2002).

Ao se confrontarem as experiências dos SRA e do Grupo da Água com a literatura sobre as diferentes tipologias acerca da participação da sociedade, identificou-se que conseguiram alcançar o nível $3^{\circ}$, caracterizado pelo envolvimento funcional - em uma perspectiva "mais braçal", cuja proposta de programação já estava pronta. No estudo sobre diferentes níveis, tipologias e caracterizações correspondentes de participação, ilustrado no Quadro 2, Rozemberg (2002) salienta que um número pequeno de projetos pode ser classificado nos níveis $4^{\circ}$ (interatividade) e $5^{\circ}$ (mobilização autônoma). Isso porque ambos pressupõem uma participação mais intensa e com grande envolvimento da sociedade ou de grupos em todas as etapas do processo. Tal intensidade participativa não foi registrada nos Seminários Regionais da Água nem no Grupo do Água, por isso os níveis $4^{\circ}$ e $5^{\circ}$ estão sem indicação no Quadro respectivo. No caso em pauta, embora as experiências em 
Água Doce tenham conseguido ampliar parcerias para obtenção de algum financiamento e certo apoio técnico, não se avançou no estabelecimento de redes nem em termos de continuidade das ações e das iniciativas (SRA e Grupo da Água). Por exemplo, ações de educação ambiental (EA) têm se restringido ao ambiente escolar.

A literatura aponta que a EA se encontra envolta de idealismo e a economia mantém seu pragmatismo. Na arena política, por meio do Estado, o discurso ambientalista é ambivalente pelo fato de se manter refém do modelo econômico, gerador de problemas ambientais. Assim, é preciso ir além do discurso e das ações isoladas (BORGES; SANTOS, 2012; GOERGEN, 2010; REIGOTA, 2001).

Tais autores entendem que a Educação Ambiental é um dispositivo que confere o exercício da cidadania, apresentando a possibilidade de incorporação de novas práticas, hábitos e atitudes diante de problemas que afetam o ambiente (BORGES; SANTOS, 2012; GOERGEN, 2010; REIGOTA, 2001). No entanto, ainda falta muito para se chegar a um consenso relativo às percepções acerca da gravidade dos problemas ambientais. Não negando avanços, constata-se enorme distância entre população, setor produtivo, educação e esfera política para o enfrentamento desses problemas. Falta o ser humano alcançar uma "racionalidade ambiental" (GOERGEN, 2010, p. 20). Para Fonseca et al. (2007, p. 38), é preciso entender que a água é finita, e esse pode ser o mote da educação ambiental.

\section{Considerações finais}

Neste artigo, as questões ambientais foram brevemente situadas, especificamente envolvendo a água, e realizou-se a análise de ações ambientais em Água Doce, município catarinense produtor de água. Utilizando processos participativos, de forma articulada, alcançou-se certo protagonismo da sociedade, o qual, infelizmente, mostrou-se limitado, pois as estratégias de participação não conseguiram ultrapassar o que comumente se faz um envolvimento mais instrumental da sociedade. Apesar disso, as ações conferem caráter de inovação e originalidade nas iniciativas, a partir de criações coletivas e do seu próprio delineamento.

Retomando a problemática apresentada na introdução deste artigo - quando se perguntou: apesar do arcabouço legal (Lei no 9.433), de programas governamentais (Comitês de Bacias Hidrográficas) e da crise hídrica recente, o que poderia explicar a baixa adesão da sociedade às ações envolvendo questões ambientais (água) e a postura apenas retórica da gestão pública, que não prioriza o tema da água na sua agenda? -, pode-se dizer que, com relação à sociedade aguadocense, como o município Água Doce apresenta grande quantidade de nascentes e rios, parece haver baixa percepção de riscos ambientais ou de crises hídricas, visto que se trata de uma privação ainda não sentida. Ou seja, conforme colocado anteriormente, pode ser que haja certa "cultura de abundância".

Já no caso dos gestores públicos e políticos do município, além de comungarem da mesma percepção exposta no parágrafo anterior, entendese que é possível que as demandas exigidas pelo cotidiano (melhoria de estradas, atendimento ao setor produtivo, dentre outras) do poder executivo de Água Doce acabem se sobrepondo e o tema da água não seja priorizado na agenda.

Para maior envolvimento da população nas questões ambientais - em específico no tema água -, faz-se necessário repensar a forma de propor o enfrentamento às fragilidades detectadas no processo. Pode-se dizer que ainda se identifica grande dificuldade na percepção da população sobre as questões envolvendo a água como um bem finito. Da mesma forma, a gestão pública (legislativo e executivo) não parece se sensibilizar em uma perspectiva que possa favorecer a prioridade de temas ambientais na sua agenda de política pública.

Assim, as reflexões realizadas neste artigo poderão instrumentalizar a elaboração, prevista para 2020, do Plano de Recursos Hídricos da Bacia do Rio do Peixe e Bacias Contíguas, no que diz respeito tanto à percepção da sociedade quanto ao envolvimento público dos poderes executivo e legislativo municipais em questões ambientais - no caso, as relativas à água. 


\section{Notas}

1 Os SRA de 2016 e 2017 contaram com financiamento da FAPESC - Edital Pró-eventos.

2 Parâmetros de referência de índices: 0,000-0,499 baixo; 0,500 - 0,624 médio (FEDERAÇÃO CATARINENSE DE MUNICÍPIOS, 2018).

3 Em junho de 2019 houve alteração dessa Portaria e até o momento ainda não foi publicada nova legislação.

\section{Referências}

BORGES, Maria das Graças Medeiros; SANTOS, Elizabeth da Conceição. Educação ambiental como articuladora para a gestão ambiental do território: a preservação das nascentes do Igarapé do Mindu - Manaus. Revista Geonorte, v. 3, n. 4, p. 113-126, 2012. Edição especial.

BRASIL. Lei no 9.433, de 8 de janeiro de 1997. Institui a Política Nacional de Recursos Hídricos e cria o Sistema Nacional de Gerenciamento de Recursos Hídricos regulamenta o inciso XIX do art. 21 da Constituição Federal, e altera 0 art. $1^{\circ}$ da Lei $\mathrm{n}^{\circ}$ 8.001, de 13 de março de 1990, que modificou a Lei $n^{\circ} 7.990$, de 28 de dezembro de 1989. Diário Oficial da União, Brasília, DF, 9 jan. 1997. Seção 1, p. 470.

BRASIL. Agência Nacional de Águas. Manual de Usos Consuntivos de Água no Brasil. Brasília: DF: ANA, 2019.

CONSELHO

MUNICIPAL

DE

DESENVOLVIMENTO RURAL. Planejamento Estratégico para o Desenvolvimento Rural de Água Doce. Água Doce: Prefeitura do Município de Água Doce, 2012.

DE MARCO, Bem Hur; TREVISOL, Joviles. O Meio Ambiente nos municípios de Santa Catarina: panorama das condições ambientais e dos instrumentos de gestão. Joaçaba: Editora Unoesc, 2007.

FEDERAÇÃO CATARINENSE DE MUNICÍPIOS. Sistema de Indicadores de Desenvolvimento Municipal Sustentável (IDMS). IDMS de Água
Doce - 2018. Disponível em: <https://indicadores. fecam.org.br/indice/municipal/ano/2019/ codMunicipio/5>. Acesso em: 22 out. 2019.

FISCHER, Marta Luciane; CHUNHA, Thiago Rocha da; ROSANELI, Caroline Filla; MOLINARI, Renata Bicudo; SGANZERLA, Anor. Crise hídrica em publicações científicas: olhares da bioética ambiental. Revista Ambiente \& Água, Taubaté, v. 11, n. 3, p. 586-600, jul./set. 2016.

FONSECA, Maria das Graças Uchoa; PERES, Francisco; OLIVEIRA, Josélia; FIRMO, Araújo; UCHÔA, Elizabeth. Percepção de risco: maneiras de pensar e agir no manejo de agrotóxicos. Ciência e Saúde Coletiva, v. 12, n. 1, p. 39-50, 2007.

GOERGEN, Pedro. Teoria e ação no GT Educação Ambiental da ANPED: partilhando algumas suspeitas epistemológicas. Pesquisa em Educação Ambiental, v. 5, n. 2, p. 9-30, 2010.

GOHN, Maria da Glória. Movimentos sociais na contemporaneidade. Revista Brasileira de Educação, v. 16, n. 47, p. 333-513, maio/ago. 2011.

IBGE. Censo 2010. População de Santa Catarina. Disponível em: <https://www.ibge.gov.br/home/ estatistica/populacao/censo2010/tabelas_pdf/ total_populacao_santa_catarina.pdf $>$. Acesso em: 22 maio 2017.

INSTITUTO DE PESQUISA ECONÔMICA APLICADA. O que é? - Índice de Gini. Desafios do desenvolvimento, ano 1, n. 4, nov. 2004. Disponível em: $\quad<$ http://www.ipea.gov.br/desafios/index. php?option $=$ com_content $\&$ id $=2048$ : catid $=28 \&$ Ite mid=23>. Acesso em: 22 maio 2017.

LEFF, Enrique. La ecologia Política em America Latina: um campo em construcción. Sociedade e Estado, Brasília: UnB, v. 18, n. 112, p. 17-40, jan./ dez. 2003.

LIMA, Lucia Cecato de; MAFRA, Marli; RECH, Tassio Dresch. Educação ambiental e uso do solo em áreas de afloramento do Aquífero Guarani. In: MATOS, Izabella Barison; OLIVEIRA, Maria 
Conceição (org.). Interiorização da Educação e Repercussão na Formação. Porto Alegre: Rede UNIDA, 2016. p. 192-220.

MATOS, Izabella Barison; BARBATO, Paulo Roberto; CÔRSO, Kárin Ane; MENDES, Enio Mario; SURDI, Jociel da Rosa. Práticas Coletivas de Educação Ambiental. Água Doce: Ed. dos Autores, 2017. E-Book. Disponível em: <https://issuu.com/ simonedalmoro/docs/livro_izabella $>$. Acesso em: 29 setembro 2019.

MINAYO, Maria Cecília; MIRANDA, Aury Carvalho (org.). Saúde e Ambiente sustentável: estreitando nós. Rio de Janeiro: Fiocruz, 2002.

PRETTY, Jules. Regenerating Agriculture: polices and practice foe sustainability and self-reliance. London: Earthscan Publications, 1995.

REIGOTA, Marcos. O que é educação ambiental. São Paulo: Brasiliense, 2001, 62 p.

ROZEMBERG, Brani. Participação comunitária em programas de promoção em saúde: elementos para uma avaliação crítica de metas e pressupostos. In: MINAYO, M. C. S.; MIRANDA, A. C. de (org.). Saúde e ambiente sustentável: entrelaçando nós. Rio de Janeiro: Editora Fiocruz, 2002. p. 191-199.

SANTA CATARINA. Empresa de Pesquisa Agropecuária e Extensão Rural de Santa Catarina. Proteção de nascentes: modelo EPAGRI. Florianópolis: EPAGRI, 2012. 1 fôlder.

SANTA CATARINA. Polícia Militar de Santa Catarina. Comando de Policiamento Militar Ambiental. Portaria n002/CPMA/PMSC/2016, de 26 de outubro de 2016. Estabelece referência para orientação e aprovação dos projetos de conversão de multa simples, em serviços de preservação, melhoria e recuperação da qualidade do meio ambiente. Diário Oficial de Santa Catarina, Florianópolis, p. 3-5, 8 nov. 2016.

SANTOS, Vania Maria Nunes; JACOBI, Pedro Roberto. Educação, ambiente e aprendizagem social: metodologias participativas para geocoservação e sustentabilidade. Rev. Bras. Edu Pedagógica, Brasília, DF, v. 98, n. 249, p. 522-539, 2017.

SOUZA, Celina Estado da arte da pesquisa em políticas públicas. In: HOCHMAN, Gilberto; ARRETCHE, Marta; MARQUES, Eduardo. Políticas Públicas no Brasil. Rio de Janeiro: Fiocruz, 2007. p. 65-86.

TENÓRIO, Fernando Guilherme (org.). Cidadania e desenvolvimento local: critérios de análise. Rio de Janeiro: FGV Editora, 2012. v. 1.

TRINDADE, Larissa Lima; SCHEIBE, Luiz Fernando. Gestão das águas: limitações e contribuições na atuação dos Comitês de Bacias Hidrográficas Brasileiros. Ambiente \& Sociedade, São Paulo, v. 22, p. 1-20, 2019.

TRINDADE, Larissa Lima; SCHEIBE, Luiz Fernando; RIBEIRO, Wagner Costa. A governança da água: o caso dos comitês dos Rios Chapecó e Irani- SC. Geosul, Florianópolis, v. 33, n. 68, p. 3657, set./dez. 2018.

UNESCO. Water for a sustainable world. Paris: [s. n. $], 2015$. Disponível em: <http://unesdoc. unesco.org/images/0023/002318/231823E.pdf>. Acesso em: 22 maio 2017.

ZAGO, Sady; PAIVA, Doralice Pedroso (org.). Rio do Peixe: Atlas da Bacia Hidrográfica. Joaçaba: Editora Unoesc, 2008. 